\title{
Interactions of Candida albicans Yeast Cells, Germ Tubes and Hyphae with Human Polymorphonuclear Leucocytes in vitro
}

\author{
By A. COCKAYNE AND F. C. ODDS* \\ Department of Microbiology, University of Leicester, Leicester LE1 7RH, UK
}

(Received 26 September 1983)

\begin{abstract}
Suspensions of Candida albicans yeast cells, germ tubes and hyphae with biomass standardized by ATP measurement were compared for their relative susceptibilities to phagocytosis and intracellular killing by human polymorphonuclear leucocytes. All three forms were ingested to a similar extent, but significantly fewer yeast cells were killed intracellularly after ingestion than were filamentous forms of the fungus. Ketoconazole pretreatment significantly enhanced the susceptibility of hyphae, but not of germ tubes, to phagocytosis and intracellular killing. The opsonic requirements of the yeasts and filamentous forms for efficient phagocytosis and killing differed.
\end{abstract}

\section{INTRODUCTION}

Polymorphonuclear leucocytes (PMNs) are one of the major cell types involved in resistance to infection by the opportunistic dimorphic fungus Candida albicans (Rogers \& Balish, 1980), and the interactions between PMNs and $C$. albicans have been extensively studied in vitro (Louria \& Brayton, 1964; Yamamura \& Valdimarsson, 1977; Kagaya \& Fukazawa, 1981; Richardson \& Smith, 1981). The results of some of these studies have suggested that the ability of $C$. albicans to produce germ tubes (early hyphal outgrowths) inside phagocytic cells may be a mechanism that allows the fungus to escape intracellular killing (Louria \& Brayton, 1964; Stanley \& Hurley, 1969). Little quantitative investigation has, however, been made of the interaction of phagocytic cells and pre-formed $C$. albicans germ tubes and hyphae, despite the observation that these forms may be found together with budding yeast cells in lesions in vivo (Rogers, 1966) and must therefore be exposed pre-formed to phagocytic cells in vivo.

This situaton has arisen partly because of the difficulties inherent in manipulating filamentous forms of $C$. albicans in vitro, and partly because of problems of quantifying and standardizing the biomass of different morphological forms of the fungus for comparative assays of phagocytosis and intracellular killing. In addition, quantification of phagocytosis has proved difficult since the large size of germ tubes and hyphae precludes their total phagocytosis by single leucocytes, so that visual assessment of ingestion and killing becomes a very subjective process. Where phagocytosis of filamentous forms has been studied, standardized comparison between different forms has been absent (Diamond et al., 1978) or the methods used for quantification of phagocytosis have been subjective (Scherwitz \& Martin, 1979).

ATP bioluminescence photometry has been used for the estimation of viable biomass in a number of biological systems (Holm-Hansen, 1973), and for standardization of the viable biomass of $C$. albicans and other pathogenic fungi (Odds, 1980). This method therefore offers a useful basis for the standardization of biomass of suspensions of $C$. albicans in its different morphological forms, regardless of the shape of the suspended cells. The development of radiometric assays for quantification of phagocytosis and killing of fungi (Yamamura et al., 1977) has provided a more objective means for assessing these processes, and they can be applied to all morphological forms of $C$. albicans.

Abbretiations: EMEM, Eagle's minimal essential medium; PMN, polymorphonuclear leucocyte: SDB. Sabouraud dextrose broth. 
This paper reports the results of a comparative study of the subceptibility of different forms of C. albicans to phagocytosis and intracellular killing by human PMNs in vitro, with fungal biomass standardized in terms of ATP concentration, and phagocytosis and killing measured radiometrically. The effects of some serum factors and the antifungal drug ketoconazole on these processes were also evaluated.

\section{METHODS}

Candida albicans isolate and preparation of filamentous forms. Candida albicans 73/055, originally isolated from a routine vaginal swab, was maintained at room temperature on Sabouraud dextrose agar (Oxoid). Yeast-form inocula were prepared in Sabouraud dextrose broth (SDB), comprising mycological peptone (Oxoid), $10 \mathrm{~g}^{-1}$ and D-glucose, $40 \mathrm{gl}^{-1}$, and incubated overnight at $30^{\circ} \mathrm{C}$ in an orbital shaker set at 160 r.p.m. Germ tubes and hyphae were grown in Eagle's minimal essential medium (EMEM; Gibco) containing Earle's salts, L-glutamine and $20 \mathrm{mM}$-HEPES pH 7.4, and incubated statically in air at $37^{\circ} \mathrm{C}$ for 2 and $6 \mathrm{~h}$ respectively. The initial yeast cell concentration in all cultures was $10^{6} \mathrm{ml}^{-1}$. Under these conditions more than $95 \%$ of the inoculum formed germ tubes, and by $6 \mathrm{~h}$ only well-developed hyphae with branches and without secondary yeast cell forms were seen microscopically. The fungi were harvested by centrifugation at $2500 \mathrm{~g}$ for $5 \mathrm{~min}$, washed twice in distilled water and resuspended in EMEM $+20 \mathrm{mM}-H E P E S, \mathrm{pH} 7 \cdot 2$. The average lengths of germ tubes and hyphae were $25 \mu \mathrm{m}$ and $100 \mu \mathrm{m}$ as determined with a calibrated eyepiece graticule and phase-contrast microscopy.

Determination of ATP concentrations of $C$. albicans suspensions. The viable biomass of $C$. albicans suspensions was estimated by ATP photometry essentially as described by Odds (1980). Briefly, $0.25 \mathrm{ml}$ samples of fungal cultures

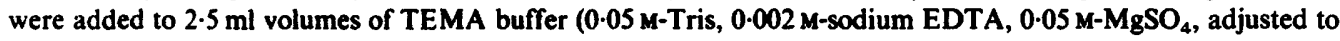
$\mathrm{pH} 7.75$ with acetic acid) that was preheated in test tubes in a boiling water bath. The mixtures were heated in the boiling water for $4 \mathrm{~min}$ and then cooled in ice-water. The ATP concentrations in the mixtures were determined by reference to a pure ATP standard solution with an integrating bioluminescence photometer (Lab-Line Instruments, Melrose Park, Illinois, USA) and partially purified luciferin-luciferase reagents.

Preparation of PMNs and sera. PMN-rich leucocyte suspensions were obtained from venous blood by the dextran sedimentation method described by Bridges et al. (1980). Leucocytes were washed twice in $10 \mathrm{ml}$ EMEM $+20 \mathrm{mM}$-HEPES pH 7.2 and were resuspended in this medium to a concentration of approximately $10^{7}$ cells $\mathrm{ml}^{-1}$

Human serum was obtained from clotted venous blood donated by healthy volunteers. Some samples of serum were heated in a water bath to $56^{\circ} \mathrm{C}$ for $30 \mathrm{~min}$ - a procedure designed to inactivate the $\mathrm{C}_{3}$ component of the complement cascade (Wilson \& Miles, 1964). Control and anti-C. albicans rabbit sera were obtained from New Zealand White rabbits. The anti-C. albicans antisera were raised against a mixture of cell wall and cytoplasmic antigens of yeast cells, germ tubes or hyphae prepared from C. albicans 73/055. Rabbits were immunized on three consecutive days of the week over a three week period, with increasing doses of antigen administered intravenously and subcutaneously. Blood was obtained from the animals three weeks after the last immunizing dose.

All sera were tested for the presence of anti-C. albicans precipitins by counter-immunoelectrophoresis against the homologous cytoplasmic extract (Odds et al., 1975). Human sera, foetal calf serum (Gibco) and control rabbit sera were all negative in these tests. Antisera raised against $C$. albicans growth forms all had an anti-C. albicans precipitin titre of $1: 32$. All sera were stored in $1 \mathrm{ml}$ lots at $-20^{\circ} \mathrm{C}$.

Phagocytosis and killing assays. The method adopted for measurement of ingestion and intracellular killing of $C$. albicans was essentially that described by Bridges $e t$ al. (1980). It involved comparison of $\left[{ }^{3} \mathrm{H}\right]$ uridine uptake by the fungus in the presence and absence of PMNs. Phagocytosed $C$. albicans cells are unable to take up $\left[{ }^{3} \mathrm{H}\right]$ uridine, and the reduction in label uptake in the presence of PMNs, compared with control uptake, was considered to be proportional to the extent of phagocytosis. Intracellular killing was measured similarly by comparing uptake of $\left[{ }^{3} \mathrm{H}\right]$ uridine in C. albicans cells released from PMNs by sodium deoxycholate treatment with a control, phagocytefree $C$. albicans suspension. Although this method may detect uptake of $\left[{ }^{3} \mathrm{H}\right]$ uridine by cells whose function is impaired although they are not killed, in practice a good correlation was found by Bridges et al. (1980) and in our preliminary experiments with data from subjective microscopic assessment of phagocytosis and intracellular killing.

PMN $C$. albicans mixtures were incubated with continuous end-over rotation ( 30 r.p.m.) in $2 \mathrm{ml}$ plastic vials (Sarstedt. Leicester, UK) at $37^{\circ} \mathrm{C}$ for $\mathrm{I} \mathrm{h}$ before uridine uptake was measured for the entire contents of the vials. After $\mathrm{l} h$ incubation in the presence of $\left[{ }^{3} \mathrm{H}\right]$ uridine, cell-associated radioactivity was collected on pre-wetted $25 \mathrm{~mm}$ diameter GFB filters (Whatman) which were then dried overnight at $80^{\circ} \mathrm{C}$. Radioactivity was counted in $3 \mathrm{ml}$ of Fisofluor I (Fisons) in a Packard PL Tri-Carb scintillation counter. All assays were performed in duplicate in the presence of $5 \%$ control human serum unless otherwise stated.

Phagocytosis and intracellular killing were calculated according to the formula:

Percentage phagocytosis or killing $=100 \times[($ control c.p.m.) - (test c.p.m.) $] /$ control c.p.m. 


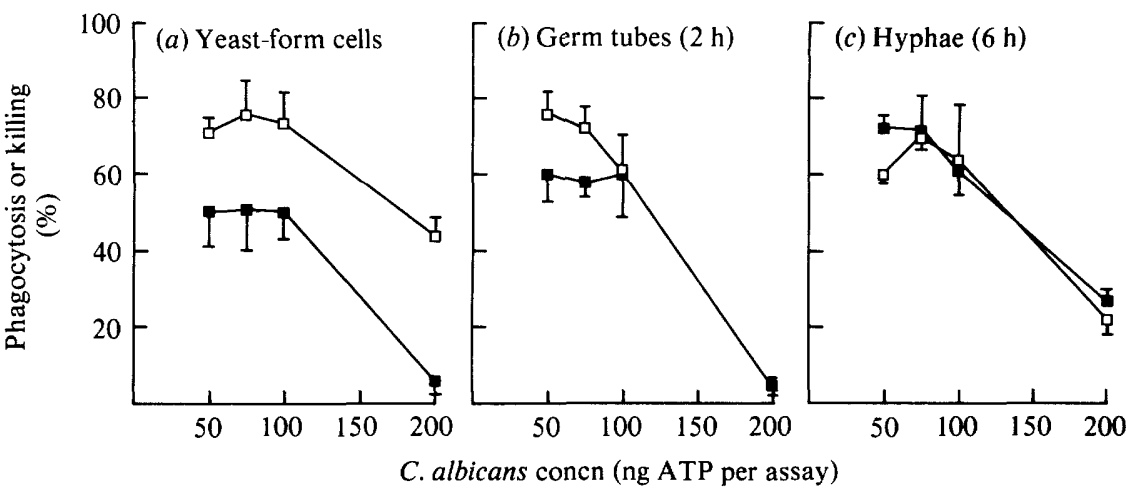

Fig. 1. Variation in phagocytosis and killing of $C$. albicans yeast forms $(a)$, germ tubes $(b)$ and hyphae $(c)$ by human PMNs at different ratios of $C$. albicans to PMNs. Suspensions of $C$. albicans were standardized by ATP bioluminescence photometry. Each point represents the mean of four separate determinations; the bars represent SD. $\square$, Phagocytosis; $\square$, killing.

The proportion of ingested $C$. albicans cells that were killed inside PMNs was calculated according to the formula: Proportion killed $(\%)=100 \times$ Percentage of $C$. albicans cells killed/Percentage of $C$. albicans phagocytosed Data were analysed statistically by the Mann-Whitney $U$ test and results are expressed as means \pm SD.

To determine the extent to which ingested yeast cells escaped phagocytosis by production of germ tubes, $C$. albicans yeast cell/PMN mixtures were sampled after 1 and $2 \mathrm{~h}$ incubation at $37^{\circ} \mathrm{C}$ and examined by phasecontrast microscopy.

\section{RESULTS}

Preliminary experiments with $C$. albicans $73 / 055$ yeast cells grown overnight in SDB showed that phagocytosis and intracellular killing were optimal at a blastospore:PMN ratio of $75 \mathrm{ng} C$. albicans ATP to $2 \times 10^{5} \mathrm{PMNs}$, an approximate numerical ratio of $2-3$ yeast cells per PMN as judged by haemocytometer counts (Fig. $1 a$ ). Further assays at this optimal ratio showed the extent of variation in data for phagocytosis and intracellular killing by PMNs obtained from seven different donors (mean percentage phagocytosis $=75 \pm 7$, mean percentage killing $=48$ \pm 10 ) and from the same donor in eight replicate assays at different times (mean percentage phagocytosis $=72 \pm 8$, mean percentage killing $=40 \pm 13$ ). There was a clear linear relationship between the ATP content of yeast cells and the cell number judged microscopically: the association between $\left[{ }^{3} \mathrm{H}\right]$ uridine uptake and cell number/ATP concentration was also linear over the range tested.

Phagocytosis and intracellular killing of yeast cells, germ tubes and hyphae

The extent of ingestion and killing of $C$. albicans germ tubes and hyphae was essentially the same over the range 50-100 ng ATP per assay (Figs $1 b$ and $1 c$ ), and there was a fall-off in phagocytosis and killing above $100 \mathrm{ng}$ ATP per assay for all three $C$. albicans growth forms tested (Fig. 1). Although the percentage of fungi phagocytosed was broadly similar for all three forms, the proportion of ingested yeast cells that were killed at the optimal $75 \mathrm{ng}$ ATP per assay was statistically significantly lower than the proportion of ingested germ tubes or hyphae that were killed. The mean proportions of organisms killed were: yeast cells, $58 \cdot 1$; germ tubes, $99 \cdot 1$; hyphae, $100.8(P<0.001$ for yeast cells vs germ tubes and yeast cells vs hyphae).

Yeast cells grown for $6 \mathrm{~h}$ in EMEM at $30^{\circ} \mathrm{C}$ showed essentially the same extent of phagocytosis and intracellular killing as yeast cells grown overnight in SDB. For yeast cells of both types, approximately $10 \%$ had formed germ tubes within PMNs after $2 \mathrm{~h}$ incubation.

\section{Effect of ketoconazole pretreatment of $C$. albicans on phagocytosis of germ tubes and hyphae}

The imidazole antifungal drug ketoconazole at a concentration of $10^{-7} \mathrm{M}$ inhibited hyphal development of $C$. albicans 73/055 after normal initial formation of germ tubes. The effect of PMNs on germ tubes and hyphae that had been grown in the presence of $10^{-7} \mathrm{M}$-ketoconazole 
Table 1. Phagocytosis and intracellular killing of C. albicans germ tubes and hyphae grown in the presence and absence of ketoconazole

Germ tubes and hyphae were grown in the presence or absence of ketoconazole for 2 and $6 \mathrm{~h}$ respectively. The ratio of $C$. albicans to PMNs was $75 \mathrm{ng}$ ATP $: 2 \times 10^{5}$ cells. The data represent the means of six separate experiments $\pm S D$.

\begin{tabular}{|c|c|c|c|c|}
\hline \multirow{2}{*}{$\begin{array}{l}\text { Ketoconazole } \\
\text { addition }\end{array}$} & \multicolumn{2}{|c|}{ Phagocytosis $(\stackrel{0}{\%})$} & \multicolumn{2}{|c|}{ Killing (\%) } \\
\hline & Germ tubes & Hyphae & Germ tubes & Hyphae \\
\hline $\begin{array}{l}\text { None } \\
10^{-7} \mathrm{M}\end{array}$ & $\begin{array}{l}59 \pm 18 \\
62 \pm 20\end{array}$ & $\begin{array}{l}38 \pm 16 \\
85 \pm 8\end{array}$ & $\begin{array}{l}64 \pm 9 \\
54 \pm 12\end{array}$ & $\begin{array}{l}40 \pm 14 \\
81 \pm 4\end{array}$ \\
\hline
\end{tabular}

Table 2. Effects of serum factors on phagocytosis and intracellular killing of C. albicans yeast cells, germ tubes and hyphae

The different sera were added to a final concentration of $5 \%(v / v)$. The data represent means of four separate determinations \pm SD.

\begin{tabular}{lccccccc}
\multirow{2}{*}{$\begin{array}{c}\text { Serum } \\
\text { addition }\end{array}$} & $\overbrace{\text { Yeasts }}$ & Germ tubes & Hyphae & & \multicolumn{3}{c}{ Killing (\%) } \\
\cline { 2 - 4 } Normal human & $68 \pm 13$ & $60 \pm 13$ & $68 \pm 13$ & $41 \pm 13$ & $42 \pm 14$ & $63 \pm 18$ \\
None & $27 \pm 21$ & $21 \pm 20$ & $36 \pm 13$ & $29 \pm 13$ & $18 \pm 29$ & $10 \pm 8$ \\
Heat treated & $57 \pm 7$ & $30 \pm 5$ & $13 \pm 3$ & $15 \pm 12$ & $26 \pm 15$ & $31 \pm 12$ \\
Foetal calf & $40 \pm 12$ & $45 \pm 31$ & $22 \pm 14$ & $14 \pm 19$ & $24 \pm 8$ & $27 \pm 4$ \\
Normal rabbit & $57 \pm 22$ & $21 \pm 4$ & $33 \pm 6$ & $38 \pm 32$ & $40 \pm 21$ & $39 \pm 15$ \\
Rabbit anti-Y* & $69 \pm 13$ & $20 \pm 11$ & $37 \pm 9$ & $47 \pm 24$ & $27 \pm 20$ & $41 \pm 20$ \\
Rabbit anti-G* & $70 \pm 16$ & $42 \pm 17$ & $54 \pm 17$ & $65 \pm 19$ & $45 \pm 10$ & $68 \pm 14$ \\
Rabbit anti-H* & $74 \pm 11$ & $32 \pm 12$ & $38 \pm 18$ & $38 \pm 29$ & $40 \pm 17$ & $58 \pm 9$
\end{tabular}

- Y, yeasts: G. germ tubes: $H$, hyphae.

was therefore investigated. Germ tubes grown for $2 \mathrm{~h}$ in the presence of ketoconazole were morphologically indistinguishable from control, untreated germ tubes, and they were phagocytosed and killed to a similar extent after the ketoconazole had been removed by washing (Table 1). By contrast, hyphae grown for $6 \mathrm{~h}$ in the presence of ketoconazole were unbranched, shorter, more pleomorphic and phase bright as compared with untreated hyphae, and they were phagocytosed and killed to a significantly greater extent than control hyphae after the ketoconazole had been removed by washing (Table 1).

\section{Effect of serum factors on phagocytosis and killing of C. albicans by human PMNs}

Phagocytosis of all three morphological forms of $C$. albicans tested was significantly lower in the absence of human serum than in its presence (Table 2). Heat pretreatment of serum had little effect on the phagocytosis of yeast cells, but significantly reduced phagocytosis of germ tubes and hyphae. Germ tubes and hyphae were phagocytosed to a similar extent in control and foetal calf serum but phagocytosis of yeast cells in foetal calf serum was significantly lower $(P<0.01)$ than in control serum (Table 2).

Omission of serum from the test system reduced the extent of killing of yeast cells, germ tubes and hyphae, but the effect was statistically significant $(P<0.01)$ only for the hyphae (Table 2 ). Yeast cells and hyphae were killed significantly less in heat-treated and foetal calf serum, but the reduction in killing of germ tubes was not statistically significant.

Although the data for phagocytosis and killing of all three forms of $C$. albicans tested were generally higher in the presence of homologous and heterologous rabbit anti- $C$. albicans antisera, there were no statistically significant differences between test and control experiments (Table 2). The overall percentage phagocytosis figures in the assays with rabbit serum were lower than those obtained for PMNs in the presence of human serum.

The absence of any significant effect of anti-C. albicans antiserum on the phagocytosis and killing of yeast cells was confirmed in experiments in which the precipitin titres of the rabbit 
antisera were reduced by absorption with homologous or heterologous antigen or by dilution with precipitin-negative antiserum. Reduction of antibody titre by any of these means had no significant effect on the extent of phagocytosis and killing (data not shown).

\section{DISCUSSION}

The combination of ATP photometry for the standardization of fungal biomass and a radiometric assay for phagocytosis and killing allowed an objective comparison of the susceptibility of different morphological forms of $C$. albicans to phagocytosis by human PMNs in vitro. When germ tubes and hyphae were tested in this system, results were more variable than those for yeast cells; in particular, in some assays values for phagocytosis were less than those for intracellular killing. In the majority of cases the discrepancies were only of a few percent, and were probably inevitable in a system with fairly high replicate variance in which virtually all the ingested fungi were also killed. The possibility that the high percentage killing figures for germ tubes and hyphae were due to the presence of undisrupted PMNs in the assay mixtures was considered, but microscopic examinations of the suspensions after sodium deoxycholate treatment showed that all the PMNs were lysed. Diamond et al. (1978) reported that human PMNs could damage pseudohyphal forms of $C$. albicans even though the fungus was not completely ingested, and this observation may help to explain the apparent anomaly in the data in our study.

We have shown that, when standardized on the basis of ATP concentration, C. albicans yeast cells, germ tubes and hyphae were phagocytosed to a similar extent, particularly at low $C$. albicans:PMN ratios. Yeast form cells were, however, less effectively killed than were germ tubes and hyphae except at relatively high C. albicans:PMN ratios. The higher susceptibility of germ tubes and hyphae to intracellular killing may be due to a number of factors. Although these filamentous forms may not be completely phagocytosed (Diamond et al., 1978) it is possible that localized damage at one site on the surface of germ tubes or hyphae may be sufficient to lead to the death of the fungal element. The continuity between different sections of $C$. albicans hyphal forms afforded by the septal pore (Scherwitz et al., 1978; Gow et al., 1980) could contribute to this action. The thickness and composition of $C$. albicans hyphal and yeast form cell walls differ (Chattaway et al., 1976) and cell wall structure may be important in resistance of the fungi to intracellular killing. In particular, the hyphal tip may be especially sensitive to the action of hydrolytic enzymes as this is probably the weakest site on the cell wall.

Variation in the composition and arrangement of the cell wall layers of $C$. albicans yeast cells, germ tubes and hyphae may also affect the intensity of the metabolic burst involved in the killing of ingested fungi, as has been suggested to account for the variation in the extent of killing of $C$. albicans and other Candida species by macrophages (Sasada \& Johnston, 1980). The differences in opsonic requirements of these morphological forms for both phagocytosis and killing could also relate to differences in cell surface composition and the availability of receptors and binding sites for serum complement and antibody. Yamamura \& Valdimarsson (1977) reported that complement was required for the optimal killing of C. albicans, and Diamond et al. (1978) found that yeast cells and pseudohyphae differed in their opsonic requirements. Some of our data also suggested differences in opsonic requirements between the two morphological forms (Table 2), which may again reflect differences in the surface properties of the different morphological forms.

Although previous authors have suggested that the ability of $C$. albicans yeast cells to resist intracellular killing is due to their ability to produce germ tubes and then grow out of phagocytic cells (Stanley \& Hurley, 1969), the results of our study suggest that processes other than germ tube production may be involved in the initial resistance to intracellular killing. If, however, ingested yeast cells survive the initial contact with the hydrolytic and oxidative killing mechanisms of PMNs they then seem likely to form germ tubes capable of thrusting out of PMNs as the ultimate means of escape. It has been suggested that, after phagocytic ingestion, yeast cells resistant to intracellular killing may be selected from a heterogeneous population and that such selection may be relevant in the maintenance of infection in vivo (Richardson \& Smith, 
1981). It is possible that the small proportion of yeast cells seen to produce germ tubes intracellularly in this study may represent members of a resistant population. Once such germ tubes have been produced, however, they may again be susceptible to the phagocytic and killing actions of other PMNs, although the possibility exists that germ tubes produced by resistant yeast cells may also be intrinsically more resistant to phagocytosis and killing.

The imidazole antifungal drug ketoconazole had a marked effect on the susceptibility of hyphae to phagocytosis and killing by PMNs, although it had little effect on the interaction of germ tubes and PMNs. De Brabander et al. (1980) reported that in mixed cultures of yeast cells and leucocytes, addition of ketoconazole to the system enhanced eradication of the fungus. In ketoconazole-free systems, a proportion of the ingested yeast cells survived and was able to multiply. In our studies, ketoconazole slowed the growth rate and elongation rate of hyphae, suggesting that its effect on morphology may be secondary to a generally inhibitory effect on $C$. albicans metabolism. Even so, the drug clearly affected the morphology of the fungus and may thus have altered surface properties important in resistance to attack by PMNs. Reduction in the growth rate of the fungus, enabling more efficient phagocytosis and killing by PMNs, may also explain the observed differences between the activity of this compound in vitro and in vivo (Odds et al., 1980).

Although our observations indicate differences in resistance to killing by PMNs of the different morphological forms of $C$. albicans, the limitations of this information should be recognized. PMNs represent only one aspect of the host response to $C$. albicans invasion, and the response by PMNs in vivo may be more complex than that tested in vitro. For example, Denning \& Davies (1973) found that $C$. albicans yeast cells and hyphae differed in their chemotactic properties towards phagocytic cells - a factor of considerable importance in vivo. Moreover, the suspension assay used in our study may not adequately represent the situation where $C$. albicans is growing on mucosal surfaces and access by phagocytic cells such as PMNs is limited.

A. Cockayne was supported by a Medical Research Council Studentship.

\section{REFERENCES}

Bridges, C. G., Dasilva, G. L., Yamamura, M. \& ValdimarsSon. H. (1980). A radiometric assay for the combined measurement of phagocytosis and intracellular killing of Candida albicans. Clinical and Experimental Immunolog. 42, 226-233.

Chattaway, F. W., O'Reilly, J., Barlow, A. J. E \& ALDERSLEY, T. (1976). Induction of the mycelial form of Candida albicans by hydrolysates of peptides from seminal plasma. Journal of General Microbiology 95, 335-347.

De Brabander, M.. Aerts, F., Van Cutsem, J., Van DEN Bossche, H. \& Borgers, M. (1980). The activity of ketoconazole in mixed cultures of leukocytes and Candida albicans. Sabouraudia 18, 197-210.

Denning, T. J. V. \& DAvies, R. R. (1973). Candida albicans and the chemotaxis of polymorphonuclear neutrophils. Sabouraudia 11, 210-221.

Diamond, R. D., Krzesicki, R. \& JaO, W. (1978). Damage to pseudohyphal forms of Candida albicans by neutrophils in the absence of serum in vitro. Journal of Clinical Intestigation 61, 349-359.

Gow, N. A. R., Gooday, G. W., Newsam, R. J. \& GULl. K. (1980). Ultrastructure of the septum in Candida albicans. Current Microbiolog. 4, 357-359.

Holm-Hansen, O. (1973). Empirical counting of colonies with different numbers of cells per colony. In Estuarine Microbial Ecology, pp. 73-89. Edited by L. H. Stevenson \& R. R. Caldwell. Columbia: University of South Carolina Press.
Kagaya, K. \& Fukazawa, Y. (1981). Murine defense mechanism against Candida albicans infection. II. Opsonisation, phagocytosis and intracellular killing of C. albicans. Microbiology and Immunology 25, 807818.

Louria, D. B. \& Brayton, R. G. (1964). Behavior of Candida cells within leukocytes. Proceedings of the Society for Experimental Biology and Medicine 115, 93-98.

ODDs, F. C. (1980). Laboratory evaluation of antifungal agents: a comparative study of imidazole derivatives of clinical importance. Journal of Antimicrobial Chemotherapy 6, 749-761.

Odds, F. C., Evans, E. G. V. \& Holland, K. T. (1975). Detection of Candida precipitins. A comparison of double diffusion and counter immunoelectrophoresis. Journal of Immunological Methods 7 , 211-218.

Odds, F. C., Milne, L. J. R., Gentles, J. C. \& Ball, E. H. (1980). The activity in vitro and in vivo of a new imidazole antifungal, ketoconazole. Journal of Antimicrobial Chemotherapy, 6, 97-104.

Richardson, M. D. \& SMrTH, H. (1981). Resistance of virulent and attenuated strains of Candida albicans to intracellular killing by human and mouse phagocytes. Journal of Infectious Diseases 144, 565-569.

Rogers, J. T. \& BALISH, E. (1980). Immunity to Candida albicans. Microbiological Reviews 44, 660682. 
Rogers, K. B. (1966). Candida infections in paediatrics. In Symposium on Candida Infections, pp. 179195. Edited by H. Winner \& R. Hurley. London: Livingstone.

SasadA, M. \& Johnston, R. B. (1980). Macrophage microbicidal activity: correlation between phagocytosis-associated oxidative metabolism and the killing of Candida by macrophages. Journal of Experimental Medicine 152, 85-98.

Scherwitz, C. \& MARTIN, R. (1979). The phagocytosis of Candida albicans blastospores and germ tubes by polymorphonuclear leukocytes. Dermatologica 159, 12-23.

Scherwitz, C., Martin, R. \& UeberberG, H. (1978). Ultrastructural investigation of the formation of
Candida albicans germ tubes and septa. Sabouraudia 16, 115-124.

Stanley, V. C. \& Hurley, R. (1969). The growth of Candida species in cultures of mouse peritoneal macrophages. Journal of Pathology 97, 357-366.

Wilson, G. S. \& Miles, A. A. (1964). Topley and Wilson's Principles of Bacteriology and Immunity, vol. 1, p. 266. London: Edward Arnold.

Yamamura, M. \& Valdimarsson, H. (1977). Participation of $\mathrm{C}_{3}$ in intracellular killing of Candida albicans. Scandinavian Journal of Immunology 6, 591594.

Yamamura, M., Boler, J. \& Valdimarsson, $H$. (1977). Phagocytosis measured as inhibition of uridine uptake by Candida albicans. Journal of Immunological Methods 14, 19-24. 